\title{
97. On the Velocity of Formation of the Ion Sheath along the Central Wire of a Geiger-Muiller Counter.
}

\author{
By Yasuo TorikaI and Teisuke Kodama. \\ Physical Institute, Faculty of Science, Tokyo Imperial University. \\ (Comm. by S. Nishikawa, M. I. A., Oct. 12, 1943.)
}

\section{Introduction.}

The formation of ion cloud by the discharge in the Geiger-Müller counter is limited in the neighbourhood of the central wire where the electric field is very large. Therefore an ion sheath appears around the wire after the discharge is quenched. It is well known that, in the normal condition of the Geiger-Müller counter, the ion sheath extends all along the length of the wire wherever the in tial excitation of the discharge occurs ${ }^{1,2)}$

The discharge propagates along the wire by secondary electron avalanches excited by the preceding one. The most of the electrons causing the secondary avalanche are produced within about $1 \mathrm{~mm}$ from the wire ${ }^{2,3)}$ on the contrary to Trost's suggestion ${ }^{1)}$. These secondary electrons are produced probably by very absorbable photons produced by the preceding avalanche. Thus the discharge grows forward by a number of small steps.

In the present experiment the velocity of the propagation of the discharge has been measured and the result is shown in the followings.

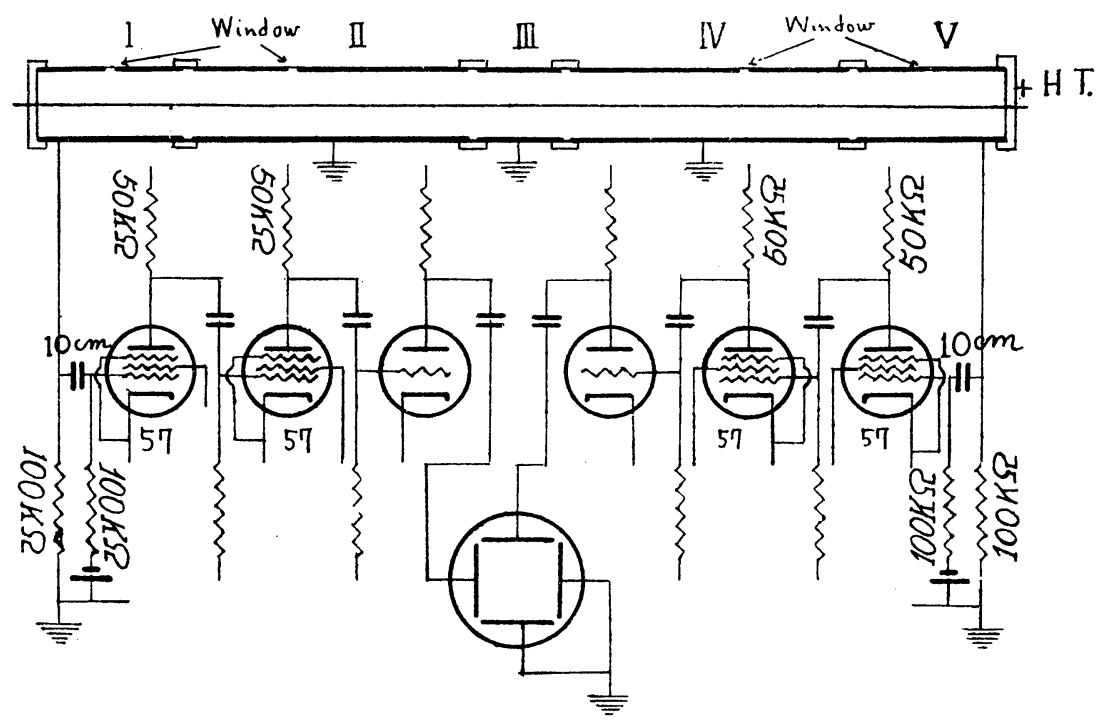

Fig. 1.

1) A. Trost; Zeit. f. Phys. 105 (1937), 399.

2) O. Minakawa: Proc. 18 (1942), 468.

3) H. Aoki and others; Nippon Sugaku-Buturi Kaisi 16 (2602), 65, 16 (2602), 388. 
[Vol. 19,

\section{Experiment.}

The counter and circuit used are shown in Fig. 1. The central wire of the counter is maintained at a positive high voltage. Tha counter wall is divided into five parts insulated each other by ebonite rings. All parts except III (Fig. 1) have mica windows for admittance of $\beta$-rays. The diameter of the counter wall is $3.8 \mathrm{~cm}$ and the total length is $55 \mathrm{~cm}$. The pulses from $\mathrm{I}$ and $\mathrm{V}$ are amplified properly and applied to $\mathrm{X}$ and $\mathrm{Y}$ axis of a cathode-ray oscillograph.
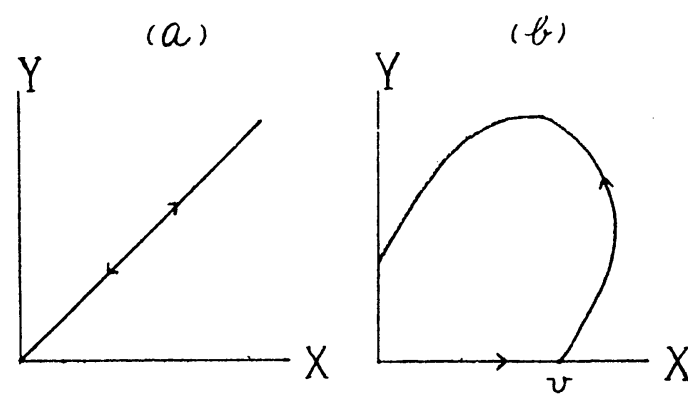

Fig. 2.

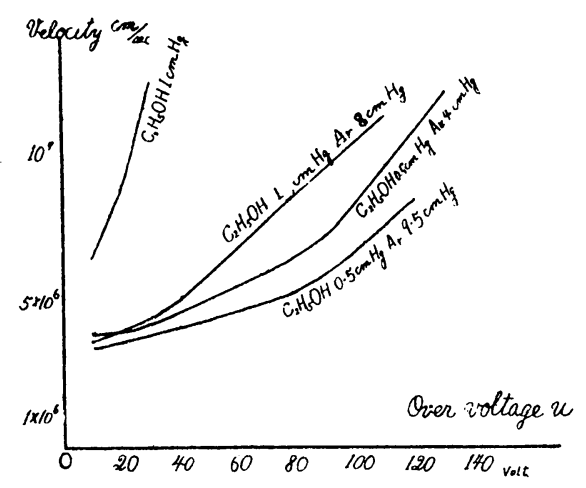

Fig. 3.

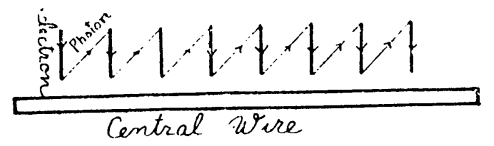

Fig. 4.

When the two pulses arise at the same instant, the figure in the oscillograph is such as shown in Fig. 2 (a). When $\beta$-rays are admitted into $\mathrm{I}$ or $\mathrm{V}$, the figures shown in Fig. 2 (b) or (c) are observed respectively. In Fig. 2 (b) the pulse in $\mathrm{V}$ is delayed by the time which corresponds to the voltage rise $v$ in the $\mathrm{X}$ axis and can be known by the pulse shape. Thus the velocity of propagation of discharge in the counter can be measured.

3. Results and Discussions.

In Fig. 3, the velocity of propagation of discharge is shown for various filling gases. The mode of propagation would be illustrated by the model shown in Fig. 4. The length of the path of electrons in each step is about $0.4 \mathrm{~mm}^{4,2)}$. Although the mobility of electrons in high field is not known, the time for one step is estimated to be about $10^{-9}$ sec. When the velocity of propagation is $10^{7} \mathrm{~cm} / \mathrm{sec}$, one centimeter of the wire is covered by about 100 steps.

4) K. Simoda and I. Ogawa ; Nippon Sugaku-Buturi Kaisi 17 (2603), 243. 
When the potential of the wall III is raised so as to suppress the field under the threshold condition, the discharge in I cannot proceed into $\mathrm{V}$, or vice versa. This is one of clear proofs that the discharge in the counter grows forward mostly by very absorbable photons. But a small fraction of discharges in I, for instance 1 in 1000, proceeds into $\mathrm{V}$, and in this case the pulses in $\mathrm{I}$ and $\mathrm{V}$ arise at the same time. This propagation would be caused by the liberation of electrons from the wall or gas by more penetrating photons than those considered in the usual propagation of discharge.

In conclusion the authors' thanks are due to Ass. Prof. H. Kumagai for his kind guidance throughout this work. The authors wish to express their thanks also to Nippon Gakujutu Sinkôkai for the financial support. 